\title{
SIRENOMELIA AND MONOMELIA WITH RENAL AGENESIS AND AMNION NODOSUM
}

\author{
BY
}

\author{
A. D. BAIN, M. M. BEATH and W. F. FLINT \\ From the Department of Pathology, University of Edinburgh, the Royal Hospital for Sick Children, Edinburgh and Kirkcaldy \\ Maternity Hospital
}

(RECEIVED FOR PUBLICATION JUNE 22, 1959)

Interest has recently been directed towards sympodia, a foetal malformation better known by the synonyms sirenomelia, sympus dipus or mermaid foetus. This malformation consists of more or less complete fusion of the lower limbs to form a single extremity.

Less frequently reported is the condition described by Ballantyne (1904) as monopodia, in which there is a single lower extremity which shows no indication that it has been derived from the fusion of two lower limbs. For this abnormality we prefer the term monomelia.

Severe dysplasia of the foetal urinary tract is apparently an invariable accompaniment of sirenomelia and monomelia. Despite the considerable number of cases described in the literature scant attention has been paid to certain other associated features in the foetus. Only occasionally is reference made to the liquor amnii, and there are no previous histological studies of the placental membranes.

\section{Case Reports}

Case 1. The mother, aged 35, para. 9, gravida 10, was perfectly well throughout her pregnancy. She was uncooperative and refused ante-natal care. At 41 weeks she went into spontaneous labour and was delivered of a male foetus weighing $1,804 \mathrm{~g}$. as a breech presentation. No doctor was present and consequently no observations were made as regards the liquor amnii. There was no history of the membranes ever having ruptured.

There was no consanguinity of the parents, nor maternal illness during the antepartum period.

Autopsy Findings. The foetus showed a single midline lower extremity measuring approximately $16 \mathrm{~cm}$. which terminated in a stump with no attached digits (Fig. 1). The face presented the characteristics usually associated with renal agenesis; the ears were large, flattened and low set; the nose flattened at the tip; the space between the eyes increased; the chin receding and the epicanthic folds prominent (Potter facies). The right hand was large, clumsy and spade-like; the left had only two digits. The anus was imperforate. There were no external genitalia.

The only abnormalities noted on internal examination were small hypoplastic lungs and total absence of both kidneys. Two testes were found in the pelvis.

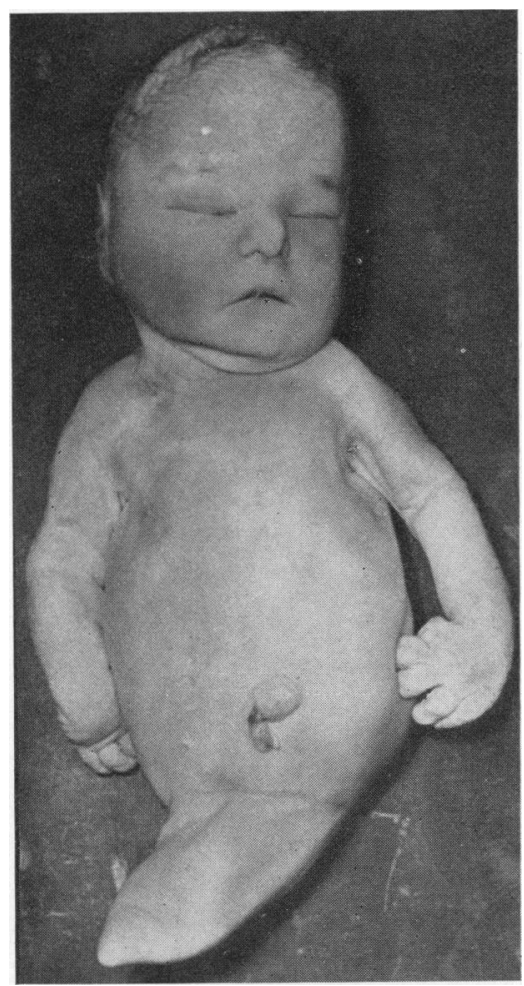

FIG. 1.-Case 1. Monomelic foetus showing large spade-like hands.

Case 2. The mother, aged 19 , para 0 , was perfectly well throughout her pregnancy. Although there was no doubt as to the date of her last menstrual period the uterus was found to be consistently small for the estimated period of gestation. At the forty-second week of her 
pregnancy she went into spontaneous labour and was delivered of a stillborn male foetus, weighing 1,850 g., as a breech presentation. The membranes were intact up to the time of delivery and no escape of liquor was noticed.

There was no consanguinity of the parents, nor any history of maternal illness during pregnancy.

AuTOPSY FINDINGS. The foetus showed features identical with Case 1, with a single lower extremity, Potter facies, large spade-like hands, absence of external genitalia and anal atresia.

Internal examination showed that the kidneys were absent and the lungs typically hypoplastic. Two testes were found in the pelvis.

Case 3. The clinical case records could not be traced and consequently no maternal history was available.

Autopsy Findings. The foetus weighed 1,200 g. and presented the typical deformity of sirenomelia, there being a single fused lower limb terminating in a foot on which there were two great toes (Fig. 2). The foetus

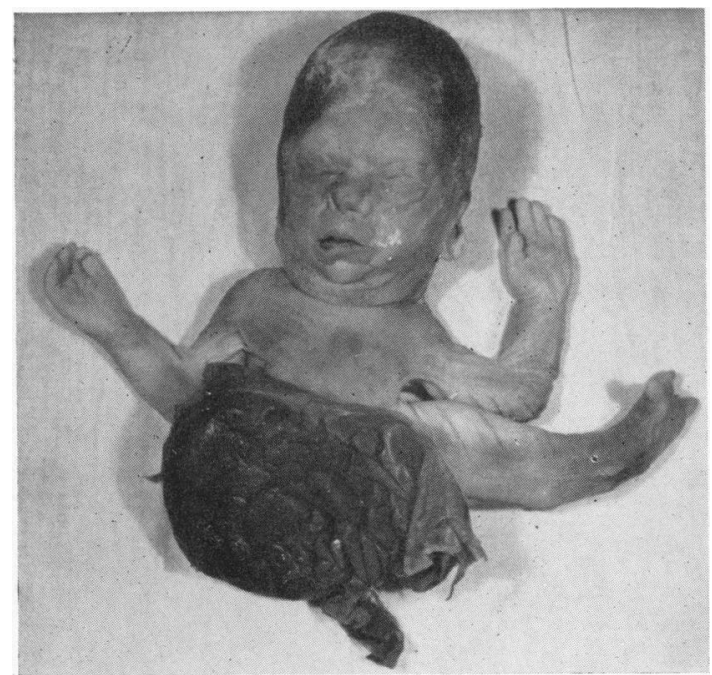

FIG. 2.-Case 3. Sirenomelic foetus with exomphalos.

showed the Potter facies, large spade-like hands, imperforate anus and no external genitalia.

There was a large exomphalos which contained the greater part of the abdominal viscera. The kidneys were absent and the internal genitalia could not be found. The lungs were hypoplastic.

Case 4. The mother was a primagravida who had excessive vomiting during early pregnancy. The uterus was found to be consistently small for the period of gestation. At 34 weeks she had an episode of vaginal bleeding and about this time also developed ankle oedema. At 44 weeks she went into spontaneous labour and was delivered of a female foetus as a vertex L.O.A. weighing $2,300 \mathrm{~g}$. The membranes were intact up to the time of delivery, and no escape of liquor was noticed.

There was no consanguinity of the parents. The only previous maternal illness was tuberculosis of the bones during childhood.

Autopsy Findings. The foetus was a typical example of sirenomelia, with a single lower limb composed of elements of two fused limbs. The foetus showed the typical Potter facies, and the hands were large and spade-like (Fig. 3). There were no external genitalia and the anus was imperforate.

Internal examination revealed small hypoplastic lungs, complete absence of both kidneys, an enterogenous cyst

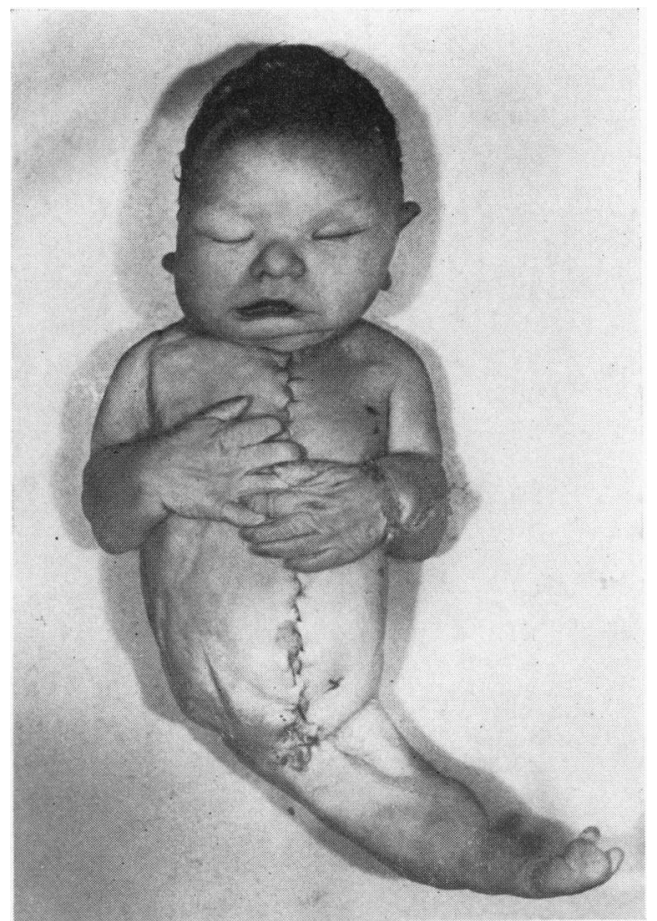

FIG. 3.-Case 4. Sirenomelic foetus showing Potter facies and large spade-like hands.

on the posterior abdominal wall, normal fallopian tubes and ovaries and a vestigial uterus but no vagina.

\section{Placental Examination}

Case 1. The placenta weighed $350 \mathrm{~g}$. The foetal surface and membranes were found to be studded with numerous small whitish nodules approximately 1-2 $\mathrm{mm}$. in diameter. These were firmly adherent to the amnion and presented the appearance typical of amnion nodosum. The maternal surface of the placenta showed no abnormality. The umbilical cord contained three vessels. 
Microscopical examination of the membranes confirmed the presence of amnion nodosum typified by aggregations of epidermal squames embedded on the surface of the amnion. The placental tissue itself was normal.

Cases 2 and 3. No note was made in the macroscopical examination of any abnormal appearance of the amnion. Retrospective microscopical examination of sections of the membranes revealed the characteristic lesion of amnion nodosum.

Case 4. The placenta was not submitted for examination.

\section{Radiological Report}

Radiological examination of the monomelic foetuses (Cases 1 and 2) revealed the single lower limb to consist of a femur and part of a tibia (Fig. 4).

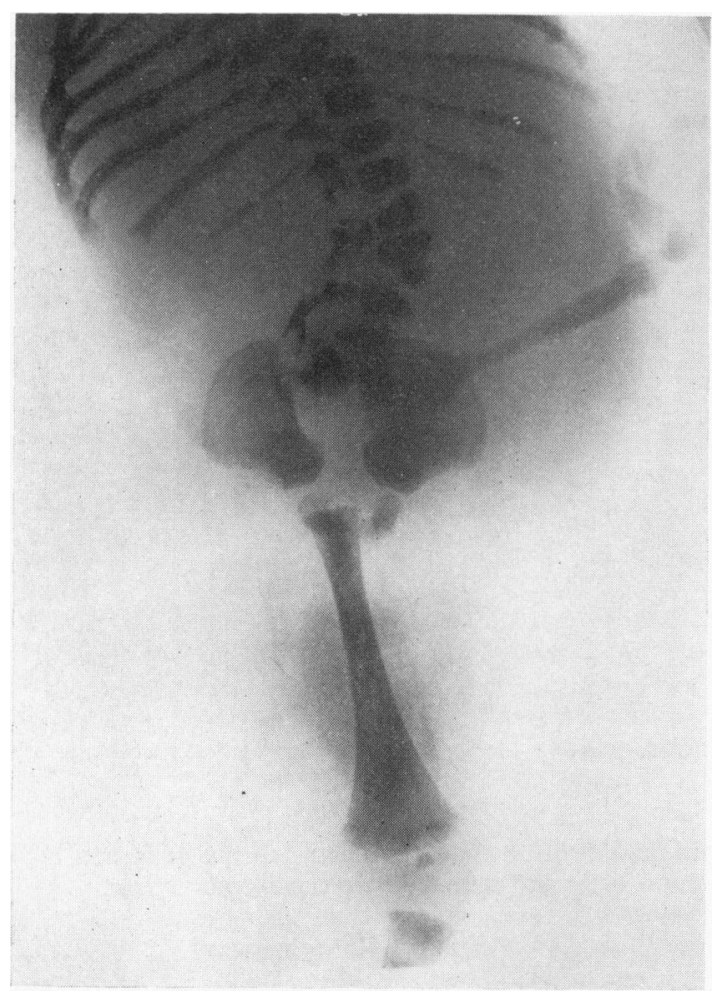

FIG. 4.-Radiograph of monomelic foetus showing lower extremity to be composed of a femur and part of a tibia.

The other abnormalities included hemivertebrae of the dorsal spine.

In the sirenomelic foetuses (Cases 3 and 4) there was fusion of the lower limbs with two femora and two deformed tibia (Fig. 5). No fibulae were present, but there were irregular areas of ossification in the site usually occupied by these bones. There were no tarsal bones but a 'bifid' single foot with irregular metatarsal and phalangeal bones.

\section{Discussion}

Babies born with either sirenomelia or monomelia are either stillborn or survive only a few hours. This fact was noted by Ballantyne (1904) and, although he was not clear as to the cause, he suggested that early death might be associated with the frequent absence of kidneys.

In the present series of cases kidneys were entirely absent, and the pulmonary hypoplasia associated with renal agenesis was a constant feature. Kidneys were, however, noted in a report by Hendry and Kohler (1956), but it is interesting that there was in this case a complete atresia of the urethra.

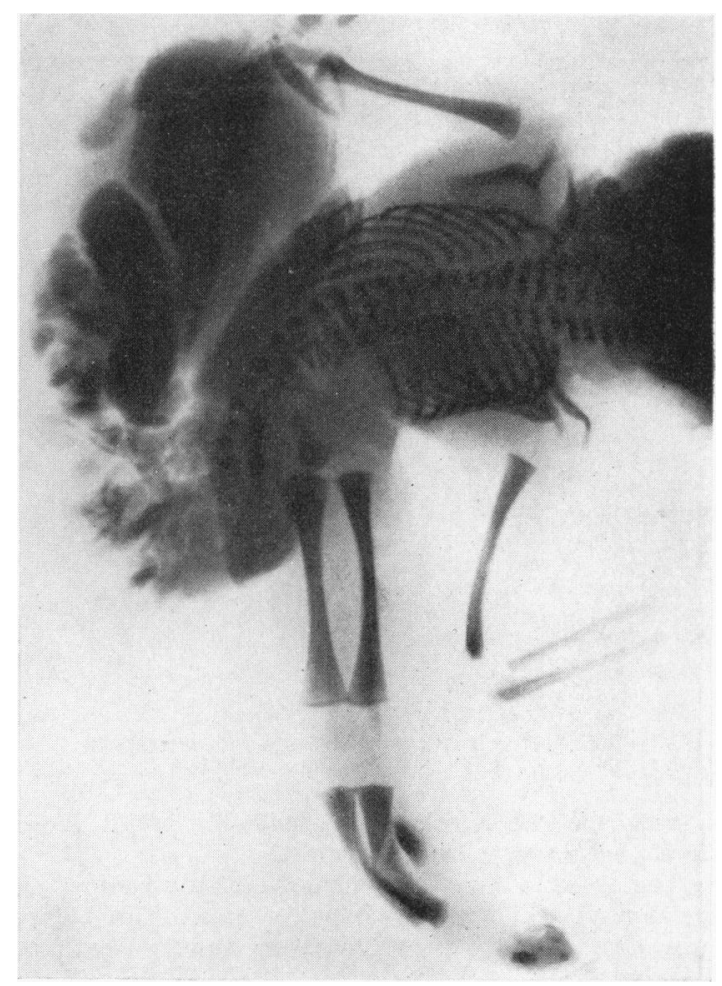

FIG. 5.-Radiograph of sirenomelic foetus demonstrating fusion of the two lower limbs.

The excellent illustrations of sirenomelia and monomelia by Ballantyne (1904), Foulkes and McMurray (1954), Hendry and Kohler (1956) and Jolly and Lamont (1958) show what is now regarded as the characteristic facial appearance first described 
by Potter (1946a and b) in association with renal agenesis. The illustrations of these authors also show the large flattened and clumsy appearance of the hands described by Bain and Scott (1960) in connexion with severe urinary tract dysplasia. Although such features have not been generally recognized as associated with sirenomelia and monomelia, Fritzsche (1955) noted the presence of Potter facies in a case of monomelia.

References to the volume of liquor amnii are generally vague and there appears to be no definite observation of oligohydramnios. Obstetrical histories were obtained in three of the present four cases. The salient points in these histories were a uterus smaller than usual for the expected period of gestation, membranes intact until the time of delivery, and no note of the escape of liquor amnii.

These facts are highly suggestive of oligohydramnios, but proof of the absence of liquor was obtained by placental examination. In three out of the four cases the placentae were examined histologically and amnion nodosum was found to be present. As shown by Scott and Bain (1958) this lesion, which consists of plaques of epithelial squames on the surface of the amnion, is found only in association with oligohydramnios.

It is of interest that Resnick (1945) noted that hydramnios, usually expected in the presence of foetal malformations, was not present in association with sirenomelia. He quotes a case described by Bauereisen (1905). This was a twin pregnancy in association with hydramnios, one of the twins being a true sympodia and the other having anal atresia but showing absence of only one kidney. It is highly probable that the hydramnios was in fact limited to the foetus with anal atresia.

Two out of the four present foetuses were delivered as breech presentations. This abnormal presentation, frequently noted in previously reported cases, is known to be favoured by the absence of foetal micturition.

Little is known as regards the aetiology of sirenomelia or monomelia, but several theories have been put forward including the suggestion that oligohydramnios is one of the causes. The oligohydramnios is obviously secondary to an embryonic defect involving the foetal kidneys or urinary tract, and although it can account for the appearances produced in the face and hands, it is unlikely to produce fusion of the lower limbs or monomelia. Absence of one umbilical artery has been cited as an aetiological factor on the assumption that it impairs blood supply to the lower limbs. However, absence of one umbilical artery is seen frequently in babies with varied congenital malformations and occasionally in apparently normal infants. The cause of these malformations could be either genetic damage or injury to the developing embryo by factors as yet unknown.

\section{Summary}

Two cases of sirenomelia and two of monomelia have been described in view of additional features not mentioned in previous reports. The Potter facies, large spade-like hands and pulmonary hypoplasia were present in all four cases. Examination of the placentae in three cases revealed the lesion of amnion nodosum, a finding indicative of oligohydramnios. Oligohydramnios was in fact noted clinically in two instances.

We conclude that severe urinary tract dysplasia, such as renal agenesis or complete urethral atresia, and its associated foetal and placental changes are a constant finding in sirenomelia and monomelia.

We wish to thank Professor R. W. B. Ellis, Professor G. L. Montgomery and Dr. A. R. Macgregor for their helpful criticism.

The photography was done by Miss C. Brydon.

\section{REFERENCES}

Bain, A. D. and Scott, J. S. (1960). Renal agenesis and severe urinary tract dysplasia. Brit. med. J., 1, 841.

Ballantyne, J. W. (1904). Manual of Antenatal Pathology and Hygiene. Green, Edinburgh.

Bauereisen, A. (1905). IX. Sitzung Fränkische Gesellschaft für Geburtshilfe und Frauenheilkunde. Erlangen. Münch. med. Wschr., 52, 721 .

Foulkes, J. F. and McMurray, J. (1954). A case of sympodia. J. Obstet. Gynaec. Brit. Emp., 61, 827.

Fritzsche, F. (1955). Ưber eine sirenoide Missbildung mit Hinweis auf Anomalien der Gesichtsbildung. Zbl. allg. Path. path. Anat., 94, 170.

Hendry, D. W. and Kohler, H. G. (1956). Sirenomelia ('Mermaid'). J. Obstet. Gynaec. Brit. Emp., 63, 865.

Jolly, H. and Lamont, E. M. (1958). Sirenomelia: Sympus dipus ('Mermaid'). Arch. Dis. Childh., 33, 226.

Potter, E. L. (1946a). Bilateral renal agenesis. J. Pediat., 29, 68. (1946b). Facial characteristics of infants with bilateral renal agenesis. Amer. J. Obstet. Gynaec., 51, 885.

Resnick, L. (1945). A case of simpus dipus. J. Obstet. Gynaec. Brit. Emp., 52, 515.

Scott, J. S. and Bain, A. D. (1958). Amnion nodosum. Proc. roy. Soc. Med., 51, 512. 